roots which are pericyclic in origin than it was of the radicle-primary root sequence of embryos. Shoot development apparently did not occur until rooted. 'nodules' were subjected to the unilateral influence of gravity.

From the results of this work it would seem that the essential conditions for embryogenesis can be duplicated in vitro. The opportunity, provided by these tissue cultures, to examine the early stages of the organization of co-ordinated root-shoot systems may eventually permit the identification and elucidation of the controlling forces of embryogenesis.

Department of Botany, D. F. Wetherelu W. HaLperin University of Connecticut, Storrs.

${ }^{1}$ Steward, F. C., Mapes, M. O., and Mears, K., Amer. J. Bot., 45, 705 (1958). ${ }^{2}$ Caplin, S. M., and Steward, F. C., Science, 108, 655 (1948).

steward, F. C., Caplin, 8. M., and Millar, F. K., Ann. Bot., 16, 58 (1955). - Steward, F. C., Amer. J. Bot., 45, 709 (1958).

\title{
Production of Pectic Enzymes by Rhizoctonia solani and Orchid Endophytes
}

Rhizoctonia solani has frequently been isolated from roots of the purple marsh orchid, Orchis purpurella, with which it may form a normal mycorrhizal symbiosis. Such endophytic strains and others isolated as pathogens from diseased crop plants often show symbiosis to $O$. purpurella protocorms in culture tests ${ }^{1,2}$. In the absence of any knowledge of the pectolytic potentiality of orchid endo. phytes a development of this investigation has been a comparative examination of the production of pectic enzymes by various Rhizoctonia strains in vitro.

The fungi used included pathogenic $R$. solani strains $R s 6$ from potato and $R s 10$ from rice (respectively parasitic and symbiotic to $O$. purpurella protocorms) and two typical orchid symbionts $R$. repens $(R r)$ from $O$. purpurella and $R$. goodyerae-repentis (Rgr) from Goodyera repens. Cultures were grown at $p \mathrm{H} \mathbf{5 \cdot 6}$ in static liquid media containing 1 per cent glucose or apple pectin as carbon source, 0.35 per cent casein hydrolysate, 0.05 per cent yeast extract, 0.1 per cent $\mathrm{KH}_{2} \mathrm{PO}_{4}, 0.05$ per cent $\mathrm{MgSo}_{4} 7 \mathrm{H}_{2} \mathrm{O}$ and trace elements. With all the strains tested, growth and sclerotial formation followed a similar pattern on the two media, pectin being only slightly less good a carbon source than glucose.

Culture filtrates were collected daily and assayed at predetermined $p \mathrm{H}$ optima for the enzymes endopolygalacturonase $(\mathrm{PG})^{3}$, endopolymethylgalacturonase $(\mathrm{PMG})^{3}$ and protopectinase. $\mathrm{PG}$ and $\mathrm{PMG}$ activity was determined viscometrically and expressed in arbitrary enzyme units per volume of culture filtrate using a modified form of the method of Roboz, Barratt and Tatum ${ }^{4}$. Protopectinase activity was expressed as a maceration index using Brown's method ${ }^{5}$.

Pectic enzyme production was negligible on glucose, but comparatively large amounts were secreted throughout the growth period on pectin media. Typical results for actively growing cultures on pectin are given in Table 1.

Table 1. PECTic Enzyare Activity of Culture FILTRates of ACtively Growing Rhizoctonia Strains on a PeCTIN Medrum

Strain symbol

Age of culture (days)

Mycelium dry wt. (mg)

PG activity (units)

Maceration index

$\begin{array}{ccc}R s 6 & R s 10 & R r \\ 4 & 4 & 7^{*} \\ 119 & 90 & 67 \\ 15.8 & 41.5 & 427.6 \\ 1.7 & 5.4 & 42.7 \\ 6.3 & 3.9 & 6.1\end{array}$

* Growth-rate of $R$. repens was lower than that of other strains.

It can be seen that all the strains have a potentiality for the secretion of each of the pectic enzymes tested, in quantities unrelated to their symbiotic or parasitic character. In particular, the pectic enzyme potential of $R$. repens is surprisingly high. It has not yet been possible to investigate enzyme production by orchid endophytes in vivo, but it seems unlikely that parasitic and symbiotic activity can be discriminated on the basis of pectic enzyme production alone. The symbiotic host endophyte complex must incorporate factors controlling the production of pectic enzymes which otherwise might give rise to a pathogenic condition. It is suggested that these factors arise only as the result of the interaction of the metabolic systems of the two partners.

So far as is known, this is the first demonstration of poctic enzyme production by symbiotic mycorrhizal fungi.

G. HADLEY

M. Pirombexon

Department of Botany,

University of Aberdeen.

1 Downie, D. G., Nature, 179, 160 (1957).

2 Harvais, G., and Hadley, G. (in preparation).

' Demain, A. L., and Phaff, H. J., Wallerstein Labs. Comm., 20, 119 (1952).

‘ Roboz, E., Barratt, R. W., and Tatum, E. L., J. Biol. Chem., 195, 459 (1952).

'Wood, R. K. S., Ann. Bot., N.S., 19, 1 (1955).

\section{MICROBIOLOGY}

\section{B-D-I,6-Glucanase in Streptomyces}

According to Reese et al. ${ }^{1}, \beta-\mathrm{D}-1,6$-glucan rarely occurs in Nature, yet many fungi are able to produce an enzyme capable of hydrolysing it. Production of $\beta-D-1,6-$ glucanase by Streptomyces has not been reported.

Previously ${ }^{2,3}$ we reported that a newly isolated microarganism produced lutease ( $\beta$-1,6-gluean-6 glucanohydrolase) when grown in a Czapek medium containing peptone and higher-molecular-weight luteose instead of sucrose. This latter substance is a $\beta-\mathrm{D}-1,6$-glucan prepared from mucilage which was produced from glucose by Penicillium aculeatum Raper and Fennell var. apiculatum Abe strain No. 2282 isolated by us from soil ${ }^{4}$.

Since the details of taxonomic position of luteaseproducing micro-organism were as yet uncertain, although the strain seemed to belong to Streptomyces species, morphological and cultural characteristics of the strain were examined. From the characteristics, that is, straight arial hyphæ (with smooth surface spore), water-green aerial mycelium, medium to strong proteolytic action, Streptomyces strain No. $O P-4-5$ was identified as belonging to Streptomyces griseus.

Tests were made to search for lutease production in Streptomyces species. Among the 89 species, 92 strains, of Streptomyces tested, Streptomyces griseus N.I.H.J.13, Streptomyces griseus N.I.H.J.107, Streptomyces parvus N.I.H.J.115, and Streptomyces niveoruber N.I.H.J.413, produced lutease more or less by previous culture for $48 \mathrm{~h}$ at $30^{\circ} \mathrm{C}$ in a Czapek modium containing peptone and higher-molecular-weight luteose instead of sucrose on a shaker. The lutease produotion of those 4 strains was defined by lutease activity assayed at each culture time. Results are shown in Figs. 1 and 2. Two strains of

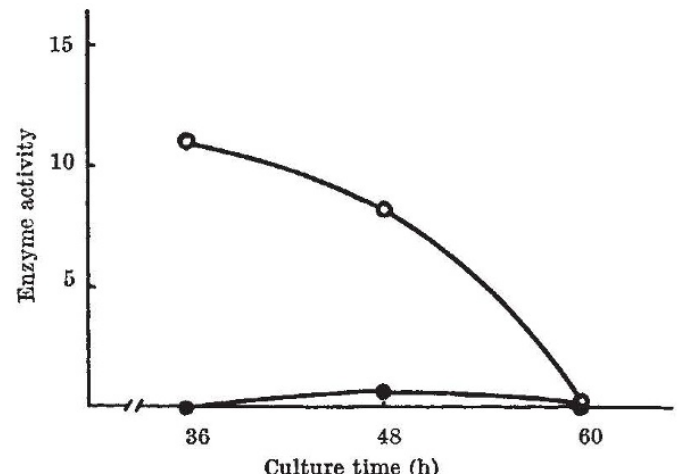

Fig. 1. Production of lutease by Streptomyces griseus N.I.H.J.13, and Streptomyces griseus N.I.H.J.107. O, S. griseus N.I.H.J.13: S. S. griseus N.I.H.J.107. Each strain was cultured in Crapek medium containing 0.2 per cent peptone and 0.5 per cent higher-molecular weigh lute sucrose at an $\mathrm{C}$ on a shaker. The assay met 